Review

\title{
The Duke University Religion Index (DUREL): A Five-Item Measure for Use in Epidemological Studies
}

\section{Harold G. Koenig ${ }^{1, *}$ and Arndt Büssing ${ }^{2}$}

1 Center for Spirituality, Theology and Health, Duke University Medical Center, Durham, NC 27503, USA

2 Professorship of Quality of Life, Spirituality and Coping, Center of Integrative Medicine, University Witten/Herdecke, Germany; E-Mail: Arndt.Buessing@uni-wh.de

* Author to whom correspondence should be addressed; E-Mail: koenig@geri.duke.edu; Tel.: +01- 919-681-6633; Fax: +01-888-244-5517.

Received: 21 September 2010; in revised form: 16 November 2010 / Accepted: 24 November 2010 / Published: 1 December 2010

\begin{abstract}
There is need for a brief measure of religiosity that can be included in epidemiological surveys to examine relationships between religion and health outcomes. The Duke University Religion Index (DUREL) is a five-item measure of religious involvement, and was developed for use in large cross-sectional and longitudinal observational studies. The instrument assesses the three major dimensions of religiosity that were identified during a consensus meeting sponsored by the National Institute on Aging. Those three dimensions are organizational religious activity, non-organizational religious activity, and intrinsic religiosity (or subjective religiosity). The DUREL measures each of these dimensions by a separate "subscale", and correlations with health outcomes should be analyzed by subscale in separate models. The overall scale has high test-retest reliability (intra-class correlation $=0.91$ ), high internal consistence (Cronbach's alpha's $=0.78-0.91)$, high convergent validity with other measures of religiosity (r's $=0.71-0.86)$, and the factor structure of the DUREL has now been demonstrated and confirmed in separate samples by other independent investigative teams. The DUREL has been used in over 100 published studies conducted throughout the world and is available in 10 languages.
\end{abstract}

Keywords: religiosity; index; validity; DUREL 
Abbreviations: ORA: organizational religious activity; NORA: non-organizational religious activity; IR: intrinsic religiosity; ER: extrinsic religiosity

\section{Background}

Research on religion, spirituality and health is expanding rapidly. In 2001, we documented that nearly 1,200 studies had quantitatively examined some aspect of the religion-health relationship [1]. In the last 10 years, more than 2,000 additional quantitative studies have been published [2]. While the research is growing, well-designed and theoretically grounded studies are still relatively rare, as the field is young and research in this area remains somewhat marginal and not well funded. One factor that may be holding back the study of religion and health is lack of a comprehensive, brief, nonoffensive, low-burden measure of religiosity that may be easily included in large cross-sectional and longitudinal studies. The Duke University Religion Index (DUREL), first published in the American Journal of Psychiatry in 1997, was designed to fill this scientific need (Table 1) [3].

Table 1. Items of the Duke University Religion Index (DUREL).

(1) How often do you attend church or other religious meetings? (ORA)

1 - Never; 2 - Once a year or less; 3 - A few times a year; 4 - A few times a month; 5 - Once a week; 6 - More than once/week

(2) How often do you spend time in private religious activities, such as prayer, meditation or Bible study? (NORA)

1 - Rarely or never; 2 - A few times a month; 3 - Once a week; 4 - Two or more times/week; 5 - Daily; 6 - More than once a day

The following section contains 3 statements about religious belief or experience. Please mark the extent to which each statement is true or not true for you.

(3) In my life, I experience the presence of the Divine (i.e., God) - (IR)

1 - Definitely not true; 2 - Tends not to be true; 3 - Unsure; 4 - Tends to be true; 5 - Definitely true of me

(4) My religious beliefs are what really lie behind my whole approach to life - (IR)

1 - Definitely not true; 2 - Tends not to be true; 3 - Unsure; 4 - Tends to be true; 5 - Definitely true of me

(5) I try hard to carry my religion over into all other dealings in life - (IR)

1 - Definitely not true; 2 - Tends not to be true; 3 - Unsure; 4 - Tends to be true; 5 - Definitely true of me

The five-item scale assesses the three major dimensions of religious involvement identified at a National Institute on Aging and the Fetzer Institute conference (16-17 March 1995) on Methodological Approaches to the Study of Religion, Aging, and Health: organizational, nonorganizational, and intrinsic or subjective religiosity. Organizational religious activity (ORA) involves public religious activities such as attending religious services or participating in other group-related religious activity (prayer groups, Scripture study groups, etc.). Non-organizational religious activity 
(NORA) consists of religious activities performed in private, such as prayer, Scripture study, watching religious TV or listening to religious radio. Intrinsic religiosity (IR) assesses degree of personal religious commitment or motivation. IR has been compared to extrinsic religiosity (ER), a form of religiosity mainly "for show" where religiosity is used as a means to some more important end (financial success, social status, comfort, or as a congenial social activity), rather than for religion's sake alone. IR, in contrast, involves pursuing religion as an ultimate end in itself. Allport and Ross defined IR as follows: "Persons with this orientation find their master motive in religion. Other needs, strong as they may be, are regarded as of less ultimate significance, and they are, so far as possible, brought into harmony with the religious beliefs and prescriptions. Having embraced a creed, the individual endeavors to internalize it and follow it fully. It is in this sense that he lives his religion." [4].

\section{Development of the DUREL}

The DUREL is composed of items that capture each of the three dimensions of religiosity described above. The first two items of the index (ORA and NORA) were taken from large National Institutes of Health supported community and clinical studies conducted in North Carolina (see below). The final three items were extracted from Dean Hoge's 10-item Intrinsic Religiosity Scale [5] (Table 2), a scale which itself was extracted by Hoge from the original 20-item Intrinsic-Extrinsic scale of Allport and Ross and nevertheless holds three items which refer to the ER. In the Duke Hospital Study, the Hoge scale was administered to 455 consecutively admitted medical inpatients [6]. Regression analysis was used to examine the relationship between each item on the scale and depressive symptoms, severity of medical illness, functional status, social support, and speed of recovery from depression. Principal components factor analysis of the 10-item scale revealed two major factors: an intrinsic and extrinsic factor (Table 3) [7]. Three items from the Hoge for the DUREL were then chosen based on their loading on the intrinsic factor, correlation with the total score, and relationship with health outcomes (Table 4) [7]. This three-item subscale was then added to the single items assessing ORA and NORA to form the final five-item index.

Table 2. 10-Item Hoge intrinsic religiosity scale.

1. My faith involves all of my life

2. In my life, I experience the presence of the Divine (i.e., God)

3. Although I am a religious person, I refuse to let religious considerations influence my everyday affairs (reverse score)

4. Nothing is as important to me as serving God as best as I know how

5. My faith sometimes restricts my actions

6. My religious beliefs are what really lie behind my whole approach to life

7. I try hard to carry my religion over into all my other dealings in life

8. One should seek God's guidance when making every important decision

9. Although I believe in religion, I feel there are many more important things in life (reverse score)

10. It does not matter so much what I believe as long as I lead a moral life (reverse score) 
Table 3. Principle components factor analysis of 10-item Hoge scale and item correlations with total score and with ORA and NORA.

\begin{tabular}{llllll}
\hline \multirow{2}{*}{ Item } & Factor 1 $^{\mathbf{1}}$ & Factor 2 & \multicolumn{3}{l}{ Pearson Correlation (r) } \\
\cline { 2 - 6 } & Eigenvalues & Eigenvalues & Tota score & ORA & NORA \\
\hline Hoge1 (IR) & 0.68 & -0.70 & 0.65 & 0.25 & 0.30 \\
Hoge2(IR) & 0.72 & -0.22 & 0.65 & 0.26 & 0.28 \\
Hoge3 (ER) & 0.42 & 0.61 & 0.52 & 0.24 & 0.24 \\
Hoge4(IR) & 0.79 & -0.25 & 0.72 & 0.36 & 0.35 \\
Hoge5(IR) & 0.41 & -0.90 & 0.49 & 0.18 & 0.16 \\
Hoge6(IR) & 0.79 & -0.12 & 0.74 & 0.37 & 0.35 \\
Hoge7(IR) & 0.72 & -0.90 & 0.68 & 0.33 & 0.38 \\
Hoge8(IR) & 0.77 & -0.23 & 0.70 & 0.40 & 0.46 \\
Hoge9 (ER) & 0.48 & 0.54 & 0.57 & 0.12 & 0.20 \\
Hoge10 (ER) & 0.50 & 0.53 & 0.61 & 0.30 & 0.31 \\
\hline
\end{tabular}

1 Standardized betas from regression model (with age, race, and sex controlled) unless otherwise specified

Table 4. Associations between 10 Hoge intrinsic religiosity items, religious activities, and health outcomes.

\begin{tabular}{lllllll}
\hline Item & $\begin{array}{l}\text { Social } \\
\text { Support }\end{array}$ & $\begin{array}{l}\text { Functional } \\
\text { Impairment }\end{array}$ & $\begin{array}{l}\text { Severity of } \\
\text { Med Illness }\end{array}$ & $\begin{array}{l}\text { Self-Rated } \\
\text { Depression }\end{array}$ & $\begin{array}{l}\text { Major } \\
\text { Depression }\end{array}$ & $\begin{array}{l}\text { Recovery } \\
\text { Depression }\end{array}$ \\
\hline Hoge1 & $0.19 * * *$ & 0.05 & -0.05 & -0.05 & -0.16 & 1.20 \\
Hoge2 & $0.19 * * *$ & 0.05 & 0.04 & -0.05 & -0.09 & 1.16 \\
Hoge3 & 0.03 & -0.04 & -0.01 & -0.02 & -0.09 & 1.05 \\
Hoge4 & 0.08 & 0.11 & 0.07 & 0.02 & 0.02 & 1.20 \\
Hoge5 & 0.02 & 0.10 & 0.09 & 0.05 & -0.05 & 1.20 \\
Hoge6 & $0.13 * *$ & 0.04 & 0.02 & -0.02 & -0.07 & $1.47 * *$ \\
Hoge7 & 0.06 & 0.07 & 0.02 & -0.06 & -0.10 & 1.35 \\
Hoge8 & $0.15 * *$ & 0.05 & 0.03 & 0.02 & -0.03 & 1.03 \\
Hoge9 & -0.04 & -0.05 & 0.02 & -0.05 & -0.15 & 1.11 \\
Hoge10 & 0.08 & -0.01 & -0.01 & -0.03 & -0.05 & 1.07 \\
ORA & $0.24 * * *$ & -0.09 & $-0.20 * * *$ & $-0.15 * * *$ & -0.17 & 1.09 \\
NORA & 0.08 & 0.02 & 0.04 & 0.03 & -0.06 & 1.05 \\
IR ${ }^{3}$ & $0.18 * *$ & 0.01 & 0.03 & -0.07 & -0.10 & $1.17 * *$ \\
\hline
\end{tabular}

p-values: $* * \mathrm{p} \leq 0.01, * * * \mathrm{p} \leq 0.001$

${ }^{1}$ Standardized betas from regression model (with age, race, and sex controlled) unless otherwise specified; ${ }^{2}$ Hazard ratio for speed of recovery from depression (using a Cox Proportional Hazards model controlling for family psychiatric history, age, sex, and severity of medical illness controlled; methods described in detail elsewhere [6]); ${ }^{3}$ Hoge2 + Hoge6 + Hoge7 (3-item subscale used in DUREL).

\subsection{Psychometric Properties}

The DUREL has an overall score range from 5 to 27 . However, since it measures three dimensions of religiosity, the DUREL really consists of three "subscales" (if one accepts the possibility of single item subscales, which is useful at least for our discussion here). Each subscale assesses a particular 
aspect of religious practice or religious devotion. In the original Duke Hospital Study (which included consecutively admitted medical inpatients aged 60 or over to Duke Hospital in Durham, North Carolina), the three-item IR subscale had a Cronbach's alpha of 0.75 , and while it was strongly correlated with Hoge's original 10-item IR scale $(r=0.85)$, it was only moderately correlated with the first single-items of the DUREL, ORA $(r=0.40)$ and NORA $(r=0.42)$. Further analysis of the threeitem IR subscale has found that the one item on the subscale best predicts the total IR subscale score (and original 10-item Hoge scale score) ("My religious beliefs are what really lie behind my whole approach to life").

Studies of the DUREL's psychometric properties by other investigators have also found it to be a reliable and valid measure of religiosity. The two-week test-retest reliability of the DUREL is high (intra-class correlation coefficient of 0.91) [8]. The internal consistency (Cronbach's alpha between 0.78 and 0.91 ), convergent validity with other established measures of religiosity ( $r$ 's $=0.71-0.86$ ), and factor structure of the DUREL have now been demonstrated and confirmed in three separate samples by investigative teams independent from our group $[9,10]$.

\subsection{Population Norms}

The first two items of the DUREL (ORA and NORA) have been administered to almost 7,000 persons aged 18 to 90 participating in the National Institute on Aging's Established Population for Epidemiologic Studies in the Elderly, the National Institute of Mental Health's Epidemiologic Catchment Area survey, and the National Institute of Mental Health-supported Duke Hospital Study (which included the other three-items of the DUREL as well). These are random samples of adults aged 65 or over (NIA EPESE) and of community-dwelling adults all ages (NIMH ECA study), both conducted in central North Carolina. Thus, there are normative data on response rates in both clinical and community populations (Table 5) [11].

Table 5. Reference values (distributions and average scores in North Carolina) for individual items in DUREL.

\begin{tabular}{llllll}
\hline & $\begin{array}{l}\text { ECA }^{\mathbf{1}} \\
\text { \% (n) }\end{array}$ & $\begin{array}{l}\text { ECA }^{\mathbf{2}} \\
\mathbf{\%}\end{array}$ & $\begin{array}{l}\text { EPESE }^{\mathbf{3}} \\
\mathbf{\%}(\mathbf{n})\end{array}$ & $\begin{array}{l}\text { EPESE }^{\mathbf{4}} \\
\mathbf{\%}\end{array}$ & $\begin{array}{l}\text { DUKE }^{\mathbf{5}} \\
\text { \% (n) }\end{array}$ \\
\hline (1) How often do you attend church or other religious meetings? & & \\
1. Never & $13.3(394)$ & 14.8 & $15.8(626)$ & 17.4 & $9.2(42)$ \\
2. Once a year or less & $7.3(215)$ & 8.1 & $5.4(214)$ & 5.5 & $11.0(92)$ \\
3. A few time a year & $16.6(492)$ & 19.1 & $7.5(299)$ & 6.9 & $13.8(155)$ \\
4. A few times a month & $19.8(587)$ & 21.0 & $18.1(718)$ & 15.8 & $12.5(57)$ \\
5. Once a week & $28.9(855)$ & 24.0 & $33.8(1341)$ & 35.0 & $32.5(148)$ \\
6. More than once/wk & $14.1(419)$ & 12.9 & $19.4(770)$ & 19.4 & $20.9(95)$ \\
Total $N$ & 2962 & & 3968 & & 455 \\
(2) How often do you spend time in private religious activities, such as prayer, meditation, or Bible study? \\
1. Rarely or never & $29.2(857)$ & 35.6 & $17.6(683)$ & 19.1 & $18.0(82)$ \\
2. A few times a month & $7.0(206)$ & 8.5 & $6.7(258)$ & 5.9 & $8.1(37)$ \\
3. Once a week & $8.9(261)$ & 7.7 & $10.7(415)$ & 10.8 & $4.6(21)$ \\
4. Two or more times/week & $9.9(290)$ & 9.6 & $8.7(336)$ & 8.2 & $10.5(48)$ \\
5. Daily (or more in EPESE) & $39.1(1149)$ & 34.4 & $56.3(2183)$ & 55.9 & $46.4(211)$ \\
\hline
\end{tabular}


Table 5. Cont.

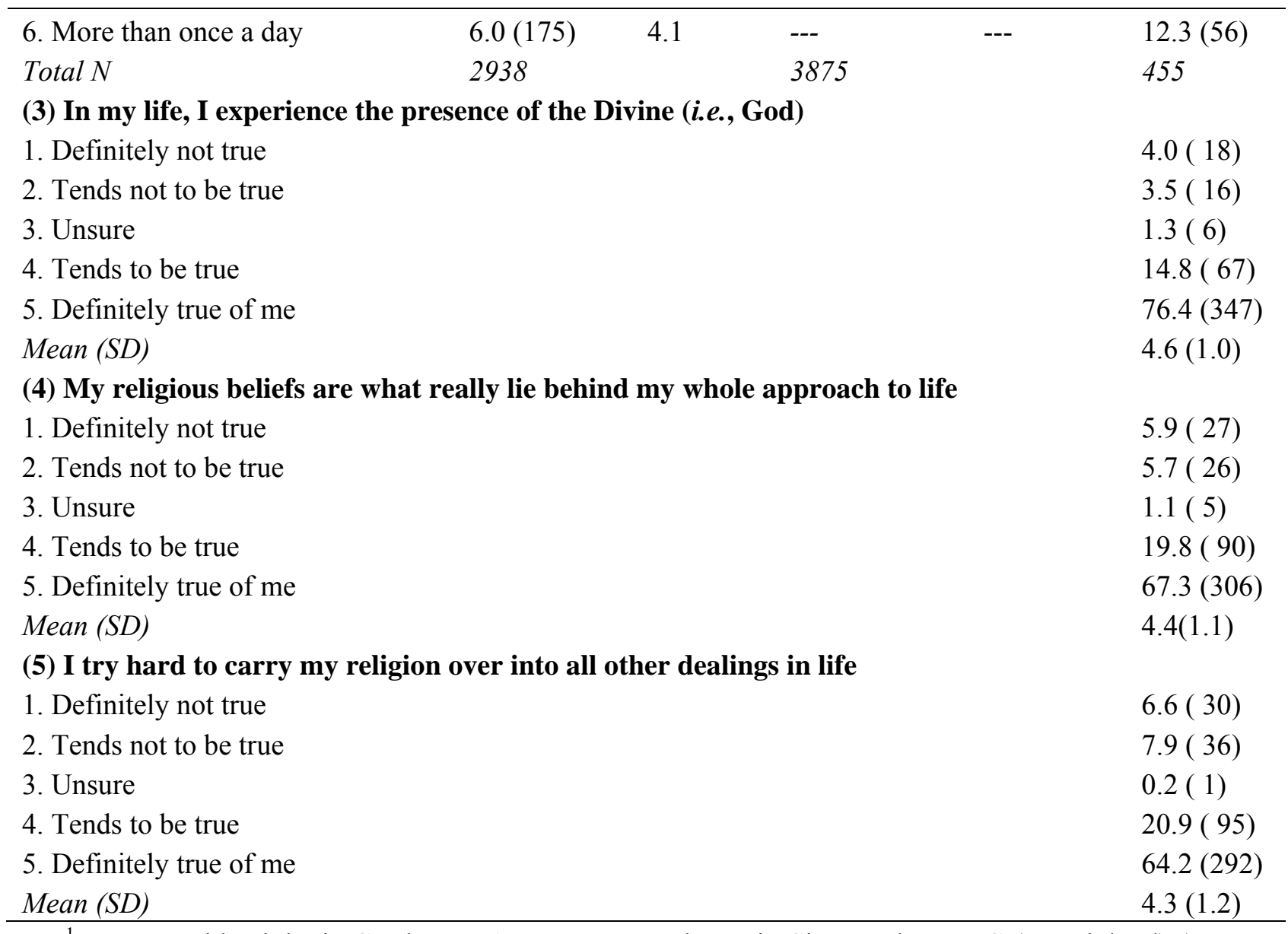

${ }^{1}$ NIMH Epidemiologic Catchment Area survey, Duke Univ Site, Durham, NC (unweighted) (age 18-97); ${ }^{2}$ NIMH Epidemiologic Catchment Area survey, Duke Univ Site, Durham, NC (weighted) (age 18-97); ${ }^{3}$ NIA Established Populations for Epidemiologic Studies of the Elderly, Duke Univ, Site, Durham, NC (unweighted) (age $\geq 65$ ); ${ }^{4}$ NIA Established Populations for Epidemiologic Studies of the Elderly, Duke Univ, Site, Durham, NC (weighted) (age $\geq 65$ ); ${ }^{5}$ Duke Hospital Study (unweighted) (hospitalized medically ill persons age $\geq 60, \mathrm{~N}=455$ )

\subsection{Scoring and Analysis}

The scoring of the DUREL is particularly important both for analysis purposes and for interpretation of results. 'Subscale' \#1 is the first question in the DUREL that asks about frequency of attendance at religious services (ORA). 'Subscale' \#2 is the second question that asks about frequency of private religious activities (NORA). Subscale \#3 consists of the final three items that assess intrinsic religiosity (IR). We do NOT recommend summing all three 'subscales' into a total overall religiosity score. Instead, investigators should examine each subscale score independently in separate regression models when examining their relationships to health outcomes. If all three subscales are included in a single statistical model, multiple collinearity between subscale scores could interfere with accurate estimate of effects for each subscale.

Furthermore, combining all three subscales in a single analysis could result in subscale scores canceling out the effects of each other. For example, in studies of depression or stroke, ORA may be inversely related to both of these disease states, while NORA may be positively related to them (since 
private religious activities like prayer are often turned to as a way of coping with the stress in response to these conditions, increasing the likelihood of a positive correlation, whereas attending religious services may serve to prevent these illnesses, resulting in negative correlations). Published studies now underscore this concern. The first 'subscale' assessing religious attendance (ORA) has been related to less depression, more social support, better physical health, lower health service use, and lower mortality [12]. The second 'subscale' assessing prayer, meditation and Scripture reading (NORA), on the other hand, has been related to poorer physical health, greater social support, and has been associated with both less and more depression, depending on population [13].

\subsection{Population Norms}

The DUREL was designed to measure religiosity in Western religions (e.g., Christianity, Judaism and Islam), and may be less accurate in its assessment of religiosity in Eastern religious traditions (e.g., Hinduism or Buddhism). However, this does not necessarily mean that the DUREL is not valid in these populations, but only that the wording may need to be adapted to those specific religious traditions. For example, the word "church" could be replaced by "temple" or "mosque" for non-Christian samples. Likewise, the word "Bible" could be replaced by "Torah" or "Koran" or "writings of Buddha." Further studies in these populations are needed to confirm or refute this claim, including validation using changes in wording. The DUREL is also not an in depth measure of religiosity, and investigators who wish to measure religiosity in greater detail may need to use a combination of measures [14]. For those wanting more comprehensive measures of religion/spirituality, Measures of Religiosity is a good resource [15]. Other limitations of the DUREL relate to the fact that religiosity is a complex construct, and there is ongoing debate about the definition and interpretation of intrinsic religiosity. These are reviewed elsewhere [14].

\section{Conclusions}

The DUREL is a brief, comprehensive, easily used measure of religiosity that is designed for use in large epidemiological studies, and is now being widely used around the world. It is a reliable measure of the three major dimensions of religiosity, although it is important to pay attention to the scoring and appropriate analysis of the subscales in relationship to health outcomes if results are to be meaningful. The DUREL has now been used in over 100 studies, and more and more investigators are choosing to use this index, especially those who want to include only a few questions on religion in their surveys and yet measure the religious domain comprehensively. The DUREL, or its subscales, has been associated with faster remission of depression, lower rates of depression, and slower progression of disability over time, as well as a host of other health outcomes, and so has proven usefulness in health outcomes research. The DUREL has now been translated into almost a dozen different languages (Spanish, Portuguese, Chinese, Romanian, Japanese, Thai, Persian/Arabic, German, Norwegian, Dutch, and Danish) for use in populations that speak these languages. 


\section{References}

1. Koenig, H.G.; McCullough, M.E.; Larson, D.B. Handbook of Religion and Health, 1st ed.; Oxford University Press: New York, NY, USA, 2001.

2. Koenig, H.G.; King, D.E.; Carson, V.B. Handbook of Religion and Health, 2nd ed.; Oxford University Press: New York, NY, USA, 2011.

3. Koenig, H.G.; Meador, K.G.; Parkerson, G. Religion index for psychiatric research. Amer. J. Psychiat. 1997, 154, 885-886.

4. Allport, G.W.; Ross, J.M. Personal religious orientation and prejudice. J. Personal. Social Psychol. 1967, 5, 432-443.

5. Hoge, D.R. A validated intrinsic religious motivation scale. J. Sci. Stud. Relig. 1972, 11, 369-376.

6. Koenig, H.G.; George, L.K.; Peterson, B.L. Religiosity and remission from depression in medically ill older patients. Amer. J. Psychiat. 1997, 155, 536-542.

7. Koenig, H.G. Developing the Duke Religion Index. Center for the Study of Religion, Spirituality and Health, Duke University Medical Center, Durham, NC, USA, 1997-1998; Unpublished work.

8. Storch, E.A.; Strawser, M.S.; Storch, J.B. Two-week test-retest reliability of the Duke Religion Index. Psychol. Rep. 2004, 94, 993-994.

9. Storch, E.A.; Roberti, J.W.; Heidgerken, A.D.; Storch, J.B.; Lewin, A.B.; Killiany, E.M.; Baumeister, A.L.; Bravata, E.A.; Geffken, G.R. The Duke Religion Index: A Psychometric Investigation. Pastoral Psychol. 2004, 53, 175-182.

10. Plante, T.G.; Vallaeys, C.L.; Sherman, A.C.; Wallston, K.A. The development of a brief version of the Santa Clara Strength of Religious Faith Questionnaire. Pastoral Psychol. 2002, 50, 359-368.

11. Koenig, H.G. Normative data on response rates in the National Institute on Aging's Established Populations for Epidemiologic Studies in the Elderly (EPESE), National Institute of Mental Health's Epidemiologic Catchment Area (ECA) Survey, and National Institute of Mental Healthsupported Duke Hospital Study. Center for the Study of Religion, Spirituality and Health, Duke University Medical Center, Durham, NC, USA, 1997-1998, Unpublished work.

12. Koenig, H.G. Medicine, Religion and Health; Templeton Press: Philadelphia, PA, USA, 2008.

13. Koenig, H.G.; Hays, J.C.; George, L.K.; Blazer, D.G. Modeling the cross-sectional relationships between religion, physical health, social support, and depressive symptoms. Amer. J. Geriatr. Psychiatr. 1997, 5, 131-143.

14. Koenig, H.G. Spirituality and Health Research: Methods, Measures, \& Analyses; Templeton Press: Philadelphia, PA, USA, 2012; in press.

15. Hill, P.; Hood, R. Measures of Religiosity; Religious Education Press: Birmingham, AL, USA, 1998.

(C) 2010 by the authors; licensee MDPI, Basel, Switzerland. This article is an open access article distributed under the terms and conditions of the Creative Commons Attribution license (http://creativecommons.org/licenses/by/3.0/). 